\title{
Broadening the Categories of Patients Eligible for Extended Venous Thromboembolism Treatment
}

\author{
Marc Schindewolf ${ }^{1}$ Jeffrey lan Weitz ${ }^{2}$ \\ ${ }^{1}$ Division of Clinical and Interventional Angiology, Swiss \\ Cardiovascular Center, Inselspital, Bern University Hospital, \\ University of Bern, Bern, Switzerland \\ 2 Thrombosis and Atherosclerosis Research Institute, McMaster \\ University, Hamilton, Ontario, Canada \\ Thromb Haemost 2020;120:14-26.
}

Address for correspondence Jeffrey lan Weitz, MD, FRCP(C), FRSC, FACP, Thrombosis and Atherosclerosis Research Institute (TaARI), McMaster University, 237 Barton Street East, C5-122, Hamilton, Ontario L8L 2X2, Canada (e-mail: Jeff.Weitz@taari.ca).

\begin{abstract}
Keywords

- anticoagulants

- body weight

- frail elderly

- renal insufficiency

- venous thromboembolism

Traditionally, venous thromboembolism (VTE) resulting from major transient risk factors (e.g., surgery or trauma) or a major persistent risk factor such as cancer, has been defined as being provoked, whereas unprovoked VTE encompasses events without an identifiable cause. These categorizations influence anticoagulant treatment duration; unlike VTE provoked by major transient risk factors, extended anticoagulation beyond 3 months is advised for patients with cancer or unprovoked VTE due to risk persistence after treatment cessation. However, some patients with VTE provoked by minor transient or minor persistent risk factors may also be candidates for extended anticoagulation therapy due to the continuing risk of recurrence. In patients who require extended therapy, vitamin $\mathrm{K}$ antagonists (VKAs) are effective but are associated with an increased risk of bleeding and various treatment burdens (e.g., anticoagulation monitoring and dose adjustment). Evaluations of extended VTE treatment with the less-burdensome direct oral anticoagulants such as apixaban, dabigatran, edoxaban, and rivaroxaban show that they are at least as safe and effective as VKAs in a broad range of patients. In addition, apixaban and rivaroxaban offer more than one dosing option, allowing tailoring of treatment to the patient's specific risk factor profile. Analysis of more granular definitions for risk factor groupings has also yielded vital information on the most appropriate strategies for the treatment of patients with specific risk factors, highlighting that extended anticoagulation treatment may benefit those with minor transient and persistent environmental and nonenvironmental risk factors who commonly receive shorter-duration therapy.
\end{abstract}

\section{Introduction}

Venous thromboembolism (VTE), comprising deep vein thrombosis (DVT) and pulmonary embolism (PE), has an annual incidence of approximately 100 to 200 per 100,000 patient-years and is associated with considerable morbidity and mortality. ${ }^{1,2}$ VTE can be categorized broadly as either provoked or unprovoked. ${ }^{3-5}$ Traditionally, VTE is considered provoked if it occurs in conjunction with major transient risk factors, such as surgery or trauma; VTE can also be provoked

by major persistent risk factors such as cancer. In contrast, if VTE occurs in the absence of such risk factors, it is considered unprovoked. The distinction between provoked and unprovoked VTE is important when considering the duration of anticoagulation treatment. In all cases, anticoagulation treatment is recommended for at least 3 months, $, 6,7$ at which point the decision to extend therapy is based on the balance between the risk of recurrent VTE if anticoagulation therapy

received June 27, 2019 accepted after revision September 26, 2019
DOI https://doi.org/ 10.1055/s-0039-3400302. ISSN 0340-6245. (c) 2020 Georg Thieme Verlag KG
Stuttgart · New York

License terms

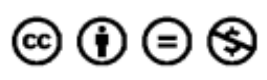


is stopped and the risk of bleeding if it is continued. Patient preferences also need to be considered, as well as cost and reimbursement for extended anticoagulation therapy.

A 3-month course of anticoagulation therapy is usually adequate for VTE provoked by major transient risk factors, provided that the risk factors have resolved. If anticoagulation therapy is stopped after 3 months in such patients, the risk of recurrence is approximately $1 \%$ at 1 year and 3\% at 5 years. ${ }^{4}$ In contrast, when anticoagulation is stopped in patients with unprovoked VTE, the cumulative risk of recurrence is approximately $10 \%$ at 1 year and 30\% at 5 years. In patients with unprovoked proximal DVT or PE, the risk of recurrence in the first 6 months after stopping therapy has been demonstrated to be significantly higher in patients who received anticoagulation for 3 months as opposed to 6 months or longer. ${ }^{4,8}$ Consequently, extended anticoagulation therapy is often prescribed for such patients. Extended anticoagulation therapy is defined by the American College of Chest Physicians as continued treatment with no specified stop date, but with periodic evaluation on at least a yearly basis to reassess the need for continued therapy and to evaluate the risk of bleeding. ${ }^{6}$ Patients with VTE provoked by major persistent risk factors such as active cancer are at the highest risk of recurrence. ${ }^{4}$ In those with metastatic disease, the risk of recurrence if anticoagulation therapy is stopped is at least $15 \%$ at 1 year; long-term prognosis is so poor that recurrence rates at 5 years cannot be determined. ${ }^{6}$ Therefore, extended anticoagulation is also prescribed for most patients with VTE provoked by active cancer. ${ }^{6}$

Accumulating evidence suggests that the traditional distinction between provoked and unprovoked VTE is overly simplistic because it fails to account for VTE provoked by minor transient risk factors, such as travel, or by minor persistent nonenvironmental risk factors, such as inflammatory bowel disease (IBD), congestive heart failure (CHF), high body mass index (BMI), thrombophilia, renal impairment, limb paralysis or paresis, prior VTE, or family history of VTE. ${ }^{9-11}$ This is problematic because the risk of VTE recurrence if anticoagulation is stopped after 3 to 6 months in such patients is higher than in patients with VTE triggered by major transient risk factors and potentially not dissimilar to the risk associated with unprovoked VTE. ${ }^{9,11}$ A list of provoking factors within each risk factor category is shown in - Table 1.

The purpose of this review is to provide guidance on which patients with VTE should be considered for extended anticoagulation therapy, taking into account new evidence regarding the less clearly elucidated minor transient or persistent risk factors and the optimal anticoagulant drug and dosing selection for such patients.

\section{Anticoagulants for the Extended Treatment of Venous Thromboembolism}

\section{Vitamin K Antagonists}

Several studies have compared the efficacy and safety of vitamin $\mathrm{K}$ antagonists (VKAs) with shorter treatment durations versus longer treatment durations in patients with provoked and unprovoked VTE. The shorter treatment dura-
Table 1 VTE provoking factors by category in the EINSTEIN EXT/EINSTEIN CHOICE baseline risk factor pooled analysis ${ }^{9}$

\begin{tabular}{|l|}
\hline Risk factor and category \\
\hline Minor transient \\
\hline $\begin{array}{l}\text { Immobilization (due to a medical disorder, excluding } \\
\text { BMI }>30 \mathrm{~kg} / \mathrm{m}^{2} \text {, and major surgery) }\end{array}$ \\
\hline $\begin{array}{l}\text { Lower limb trauma with transient impairment of mobility } \\
\text { (including orthopedic surgery/arthroscopy, but excluding } \\
\text { hip or knee replacement) }\end{array}$ \\
\hline Pregnancy, puerperium (including cesarean section) \\
\hline Air travel $>8$ hours \\
\hline $\begin{array}{l}\text { Use of estrogen therapy (hormonal contraceptive or } \\
\text { postmenopausal therapy) }\end{array}$ \\
\hline Minor persistent \\
\hline BMI > 30 kg/m ${ }^{2}$ \\
\hline CHF \\
\hline CrCl $<50$ mL/min \\
\hline Family history of VTE or known thrombophilia ${ }^{\text {a }}$ \\
\hline $\begin{array}{l}\text { IBD (diagnosed in accordance with the European Crohn's } \\
\text { and Colitis Organisation guidelines) }\end{array}$ \\
\hline Lower extremity paralysis or paresis \\
\hline Major transient \\
\hline $\begin{array}{l}\text { Major surgery or trauma (major surgery or major trauma, } \\
\text { excluding leg injuries) }\end{array}$ \\
\hline Cesarean section \\
\hline Major persistent \\
\hline $\begin{array}{l}\text { Active cancer at baseline (diagnosis or treatment }<6 \text { months } \\
\text { squamous cell skin cancer]) }\end{array}$ \\
\hline
\end{tabular}

Abbreviations: $\mathrm{BMI}$, body mass index; $\mathrm{CHF}$, congestive heart failure; $\mathrm{CrCl}$, creatinine clearance; IBD, inflammatory bowel disease; VTE, venous thromboembolism.

ancluding deficiency of antithrombin, protein $C$, protein S, factor $V$ Leiden or prothrombin gene mutation, and antiphospholipid syndrome; however, due to differences in thrombogenicity, different types of thrombophilia should be considered individually.

tions in these trials ranged from 4 weeks to 6 months, whereas longer treatment durations ranged from 12 weeks to 48 months. ${ }^{12,13}$ Overall, these trials revealed that longer treatment with VKAs reduced the risk of recurrent VTE by $80 \%$, but was associated with a threefold increase in major bleeding. ${ }^{12,13}$ Therefore, lower-intensity VKA treatment regimens were evaluated in an attempt to improve the benefitrisk profile of extended VTE therapy.

\section{Lowered-Intensity Vitamin K Antagonist Regimens}

A study comparing low-intensity warfarin therapy (target international normalized ratio [INR] 1.5-2.0) with placebo for extended therapy in patients with unprovoked VTE (who had received full-dose anticoagulation therapy for a median of 6.5 months before randomization) was stopped early after 508 patients were enrolled. Compared with placebo, low-intensity warfarin significantly decreased the rate of recurrent VTE from 
7.2 to $2.6 \%$ per 100 person-years (hazard ratio [HR], 0.36 ; $95 \%$ confidence interval [CI], 0.19-0.67; $p<0.001)$ with no significant increase in major bleeding $(0.9$ and 0.4 per 100 personyears, respectively; HR, 2.53; $95 \% \mathrm{CI}, 0.49-13.03 ; p=0.25) .{ }^{14}$ However, when low-intensity warfarin (target INR 1.5-1.9) was compared with conventional-intensity warfarin (target INR 2.0-3.0) in a study of 738 patients with unprovoked VTE who had completed $\geq 3$ months of warfarin therapy, the rate of recurrent VTE was higher with the low-intensity warfarin regimen than with the conventional-intensity regimen (1.9 and 0.7 per 100 person-years, respectively; $\mathrm{HR}, 2.8 ; 95 \% \mathrm{CI}$, $1.1-7.0 ; p=0.03)$, whereas the rates of major bleeding were similar (1.1 and 0.9 per 100 person-years, respectively; HR, 1.2 ; $95 \% \mathrm{CI}, 0.4-3.0)$. Therefore, low-intensity warfarin is associated with a higher risk of recurrent VTE than conventionalintensity therapy and does not decrease the risk of bleeding. ${ }^{15}$

\section{Direct Oral Anticoagulants}

VKAs require frequent coagulation monitoring and dose adjustments to ensure that the INR remains within the therapeutic range. Such monitoring is burdensome for patients and health care providers. ${ }^{16}$ The development of direct oral anticoagulants (DOACs) helped to overcome this problem. These agents include dabigatran, which inhibits thrombin, and apixaban, edoxaban, and rivaroxaban, which inhibit factor Xa. When given in fixed doses without monitoring, the DOACs have been shown to be at least as effective as VKAs for the treatment of patients with acute VTE but are associated with a $40 \%$ reduction in major bleeding. ${ }^{17-24}$ Because of these findings, current guidelines now give preference to the DOACs over VKAs for the treatment of VTE. $3,6,7$

The following phase III studies investigated the risk of recurrent VTE with extended DOAC therapy: RE-SONATE, 25 which compared dabigatran with placebo; RE-MEDY, 25 which compared dabigatran with warfarin; AMPLIFYEXT, ${ }^{26}$ which compared two doses of apixaban with placebo; EINSTEIN EXT, ${ }^{27}$ which compared rivaroxaban with placebo; and EINSTEIN CHOICE, ${ }^{28}$ which compared two doses of rivaroxaban with acetylsalicylic acid (ASA). Although not a formal extension study, a post hoc analysis of patients who received 3 to 12 months of anticoagulation in the HokusaiVTE trial, which compared edoxaban with warfarin, has also been conducted due to the option of a flexible therapy duration of anticoagulation in that study. ${ }^{29}$ It is important to note that there are several key differences between these studies, including in enrolment numbers, endpoint definitions, study designs, inclusion/exclusion criteria, and patient characteristics. For example, EINSTEIN EXT enrolled a higher proportion of patients with active cancer than AMPLIFY-EXT (4.5\% vs. $1.7 \%$, respectively), whereas AMPLIFY-EXT enrolled more patients with unprovoked VTE than EINSTEIN EXT (91.7\% vs. $73.7 \%$, respectively). ${ }^{26,27}$ Similarly, in the EINSTEIN CHOICE (in which $41.3 \%$ of patients had unprovoked VTE) and EINSTEIN EXT studies, the category definitions of provoked and unprovoked VTE were not in line with common practice, but reflected more contemporary definitions (e.g., VTE in patients with a family history of VTE or in those with hereditary thrombophilia or obesity was classed as "provoked by minor persistent risk factors," despite these events often being defined as "unprovoked"). ${ }^{6,9,28}$ Key details for the trials with each of these agents are shown in - Table 2 and are described more fully below.

\section{Dabigatran}

The RE-SONATE and RE-MEDY studies of extended dabigatran treatment in patients who had completed $\geq 3$ months of initial anticoagulation therapy compared dabigatran with placebo and warfarin, respectively (with planned treatment periods of 6 to 18 months and 6 to 36 months, respectively). In RESONATE, dabigatran significantly reduced the rate of recurrent or fatal VTE or unexplained death (unexplained death was an additional endpoint in RE-SONATE only) versus placebo ( $0.4 \%$ vs. $5.6 \%$; HR, 0.08 ; $95 \% \mathrm{CI}, 0.02-0.25 ; p<0.001$ ), and in REMEDY, dabigatran was noninferior to warfarin (1.8\% vs. $1.3 \%$; HR, 1.44 ; 95\% CI, 0.78-2.64; $p<0.01) .{ }^{25}$ Rates of major bleeding were not significantly higher with dabigatran than with warfarin or placebo, but the rate of the composite of major or clinically relevant nonmajor (CRNM) bleeding with dabigatran was significantly lower than that with warfarin (5.6\% vs. $10.2 \%$; $\mathrm{HR}, 0.54 ; 95 \% \mathrm{CI}, 0.41-0.71 ; p<0.001)$, but significantly higher than that with placebo (5.3\% vs. $1.8 \%$; HR, 2.92; 95\% CI, $1.52-$ $5.60 ; p=0.001)$.

\section{Apixaban}

AMPLIFY-EXT compared the treatment and thromboprophylactic doses of apixaban (5 and $2.5 \mathrm{mg}$ twice daily, respectively) with placebo in patients who had completed 6 to 12 months of anticoagulation therapy for their index VTE. ${ }^{26}$ Treatments were given for 12 months. Compared with placebo, the rate of recurrent VTE and all-cause mortality was significantly lower with both apixaban regimens (11.6\% compared with 4.2 and $3.8 \%$ with the 5 and $2.5 \mathrm{mg}$ twice daily apixaban regimens, respectively; relative risk [RR], 0.36; 95\% CI, 0.25-0.53 and RR, 0.33; 95\% CI, 0.22-0.48, respectively; $p<0.001$ for both comparisons), without an increase in the rates of major bleeding $(0.5,0.1$, and $0.2 \%$, respectively). Rates of the composite endpoint of major or CRNM bleeding with placebo, apixaban $5 \mathrm{mg}$ twice daily, and apixaban $2.5 \mathrm{mg}$ twice daily were $2.7,4.3$, and $3.2 \%$ (RR, $1.62 ; 95 \%$ CI, 0.96-2.73, and RR, 1.20; 95\% CI, 0.69-2.10), respectively. ${ }^{26}$ These results prompted a label update recommending the $2.5 \mathrm{mg}$ twice daily dose of apixaban for secondary prevention in patients who had completed at least 6 months of anticoagulation treatment for their initial VTE event. ${ }^{30}$

\section{Rivaroxaban}

EINSTEIN EXT compared rivaroxaban $20 \mathrm{mg}$ once daily with placebo for 6 or 12 months in patients who had completed 6 to 12 months of prior anticoagulation therapy. ${ }^{27}$ The rate of recurrent VTE was significantly lower with rivaroxaban than with placebo (1.3 and 7.1\%, respectively; HR, 0.18; $95 \% \mathrm{CI}$, $0.09-0.39 ; p<0.001)$. The rate of major bleeding was not significantly increased $(0.7$ and $0 \%$ with rivaroxaban and placebo, respectively; $p=0.11$ ). However, the incidence of CRNM bleeding was higher in the rivaroxaban group than in those given placebo (5.4 and $1.2 \%$, respectively); these were 


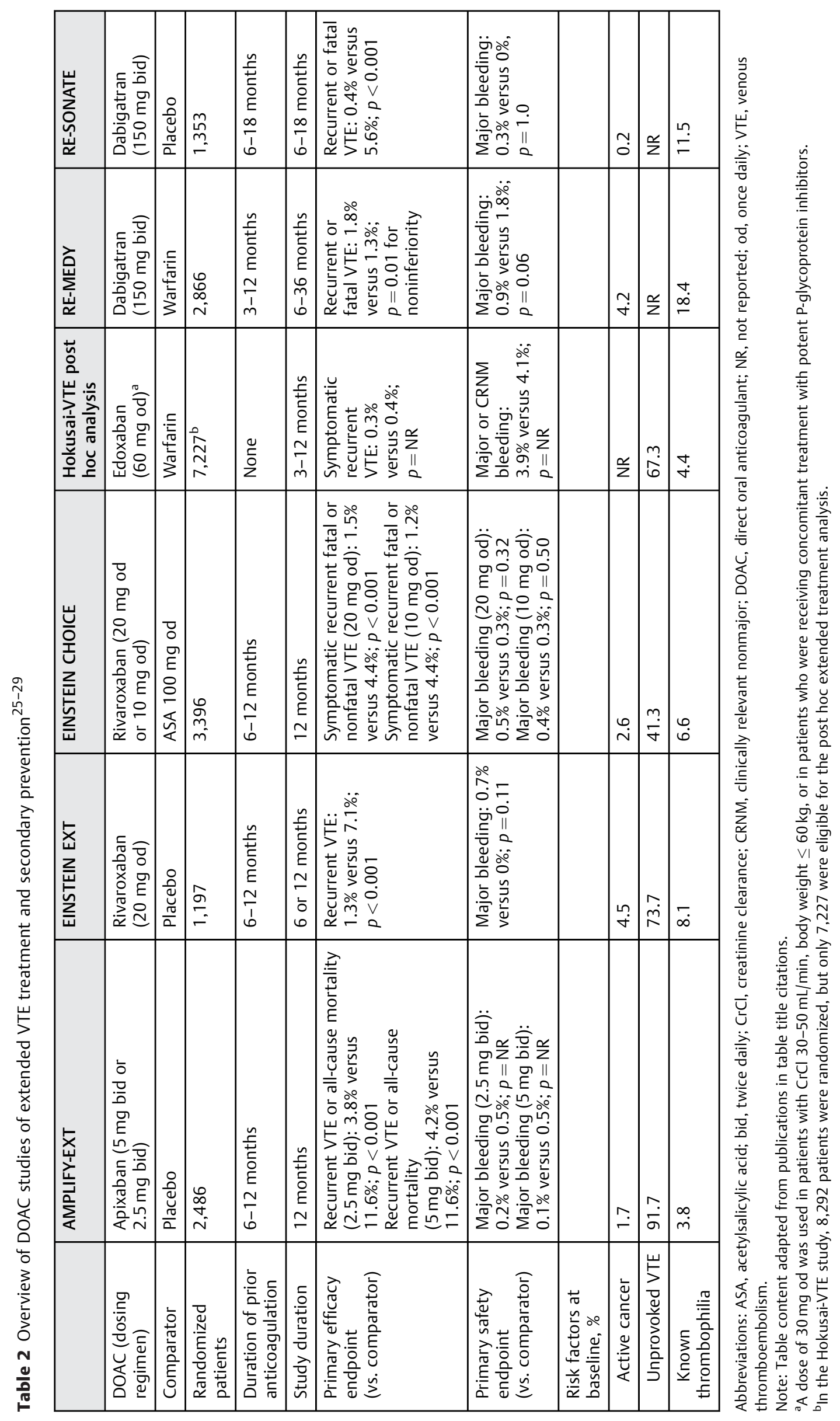


predominantly mucosal bleeding events and resumption of anticoagulation occurred in most cases. The composite endpoint of CRNM and major bleeding was 6.0 and $1.2 \%$, respectively (HR, 5.19; 95\% CI, 2.3-11.7; $p<0.001$ ).

EINSTEIN CHOICE compared the efficacy and safety of the treatment and thromboprophylactic doses of rivaroxaban (20 and $10 \mathrm{mg}$ once daily, respectively) versus ASA (100 mg once daily) for secondary prevention in 3,365 patients who had completed 6 to 12 months of anticoagulation for their index VTE, and who were at clinical equipoise with regard to the need for continued anticoagulant treatment. ${ }^{28}$ Treatments were given for up to 12 months. ASA was selected as the comparator in the EINSTEIN CHOICE trial because it has been observed to reduce the risk of VTE recurrence by approximately 32\% compared with placebo (5.1\% vs. $7.5 \%$; HR, $0.68 ; 95 \% \mathrm{CI}$, $0.51-0.90 ; p=0.008$ ) in patients for extended therapy who had received at least 3 months of anticoagulation treatment for unprovoked VTE. ${ }^{31}$ Both rivaroxaban doses significantly reduced the risk of recurrent symptomatic fatal or nonfatal VTE by approximately $70 \%$ compared with ASA. The incidence rates were $1.5 \%$ with rivaroxaban $20 \mathrm{mg}$ once daily and $1.2 \%$ with rivaroxaban $10 \mathrm{mg}$ once daily versus $4.4 \%$ with ASA (HR, 0.34; 95\% CI, 0.20-0.59 and $\mathrm{HR}, 0.26$; $95 \% \mathrm{CI}, 0.14-0.47$, respectively; $p<0.001$ for both comparisons). All groups showed similar rates of major bleeding ( $0.5 \%$ with rivaroxaban $20 \mathrm{mg}$ once daily, $0.4 \%$ with rivaroxaban $10 \mathrm{mg}$ once daily, and $0.3 \%$ with ASA). The results supported regulatory approval of a rivaroxaban label update, providing flexibility to choose the reduced rivaroxaban $10 \mathrm{mg}$ once daily dose for extended secondary prevention of VTE for most patients. ${ }^{32,33}$ In addition, the findings were broadly consistent across all patient subgroups (e.g., provoked or unprovoked VTE, low-to-moderate creatinine clearance, high body weight, hereditary thrombophilia). Further analyses of EINSTEIN CHOICE confirmed the favorable benefit-risk profile of rivaroxaban versus ASA. For every 10,000 patients treated for 1 year with rivaroxaban instead of ASA, there would be 284 (95\% CI, 106-462) fewer episodes of symptomatic VTE and major bleeding (i.e., composite net clinical benefit outcomes) with the rivaroxaban $20 \mathrm{mg}$ dose and 339 (95\% CI, 165-512) fewer events with the rivaroxaban $10 \mathrm{mg}$ once daily dose. ${ }^{34}$

A benefit-risk analysis of rivaroxaban 20 and $10 \mathrm{mg}$ versus $\mathrm{ASA}^{34}$ and a prespecified pooled analysis of data from the EINSTEIN EXT and EINSTEIN CHOICE trials to assess the risk of VTE according to baseline risk factor profiles ${ }^{9}$ are discussed further in subsequent sections of this review.

\section{Edoxaban}

The Hokusai-VTE trial compared edoxaban with warfarin for acute treatment of recurrent VTE, and all patients received at least 3 months, and up to 12 months, of anticoagulation treatment. ${ }^{35}$ Although this was not a formal extension study, due to the flexibility in duration of edoxaban treatment, a prespecified post hoc analysis was conducted to evaluate cumulative efficacy and safety at 12 months in those patients who received 3 to 12 months of treatment. ${ }^{29}$ The cumulative incidence of symptomatic nonfatal and fatal VTE between 3 and 12 months was similar between the treatment groups with incidence rates of recurrent VTE of $0.3 \%$ in the edoxaban-treated group and $0.4 \%$ in the warfarin-treated group (HR, 0.78; 95\% CI, 0.36-1.72). The cumulative incidence of major bleeding was lower with edoxaban than with warfarin (0.3\% vs. $0.7 \%$; HR, $0.45 ; 95 \% \mathrm{CI}, 0.22-0.92$ ). The cumulative incidence of major or CRNM bleeding events was 3.9\% versus 4.1\% (HR, 0.97; 95\% CI, 0.77-1.22).

\section{Guideline Recommendations Regarding the Duration of Anticoagulant Treatment for Venous Thromboembolism}

Current guidelines recommend a minimum of a 3-month course of anticoagulant treatment for all patients with VTE. ${ }^{3,6,7}$ At 3 months, the decision to stop or to extend anticoagulation therapy is based on the balance between the risk of recurrent VTE if treatment is stopped and the risk of bleeding if it is continued. Patient preference also factors into the decision. Therefore, decisions about duration of anticoagulation are both risk- and patient-focused.

A 3-month course of anticoagulation is adequate for patients with VTE provoked by major transient risk factors such as surgery or trauma because their risk of recurrence is only approximately $1 \%$ at 1 year and $3 \%$ at 5 years. ${ }^{4}$ In contrast, extended anticoagulation is recommended for patients with unprovoked VTE and a low or moderate risk of bleeding, 3,6,7,36 because the risk of recurrence if anticoagulant therapy is stopped is approximately $10 \%$ at 1 year and $30 \%$ at 5 years. ${ }^{37}$ In patients with a first unprovoked VTE and a high risk of bleeding, guidelines recommended stopping anticoagulation therapy at 3 months. ${ }^{4,8}$ Extended anticoagulation is also prescribed for most patients with VTE provoked by active cancer because such patients have a risk of recurrence of at least $15 \%$ at 1 year $^{6}$; recurrence rates at 5 years have not been determined because of the poor survival in cancer patients. ${ }^{6}$

The optimal duration of anticoagulation for patients with VTE provoked by persistent or transient minor risk factors is less clear, and guidelines do not distinguish between these categories in their treatment recommendations. If VTE is provoked by such minor factors as these, the risk of recurrence is likely to be higher than that in patients whose VTE was triggered by major transient risk factors such as surgery or trauma. Consequently, some patients with VTE provoked by minor transient or minor persistent risk factors may be candidates for extended anticoagulation therapy. A list of minor persistent and transient risk factors and the associated risks of VTE recurrence is shown in - Table 3.

\section{Broadening Anticoagulation Indications- Potential New Subgroups for Extended Venous Thromboembolism Treatment}

\section{Minor Transient Risk Factors}

Minor transient risk factors for VTE include short-term immobilization, leg injury with impaired mobility (e.g., a plaster cast), long-distance travel ( $>8$ hours), pregnancy and puerperium, and use of estrogen therapies. ${ }^{9,11}$ In a metaanalysis of data from prospective cohort and randomized 


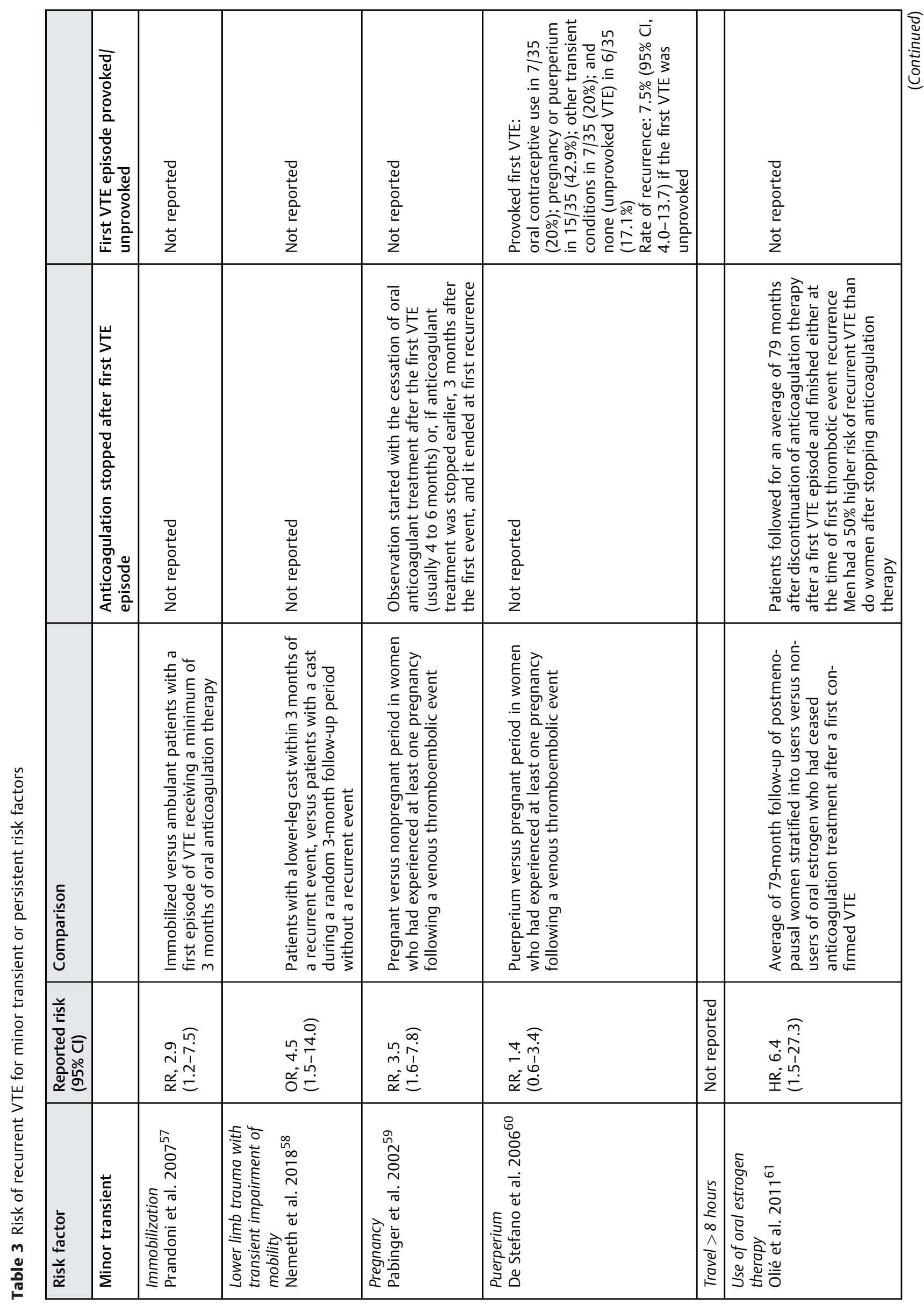




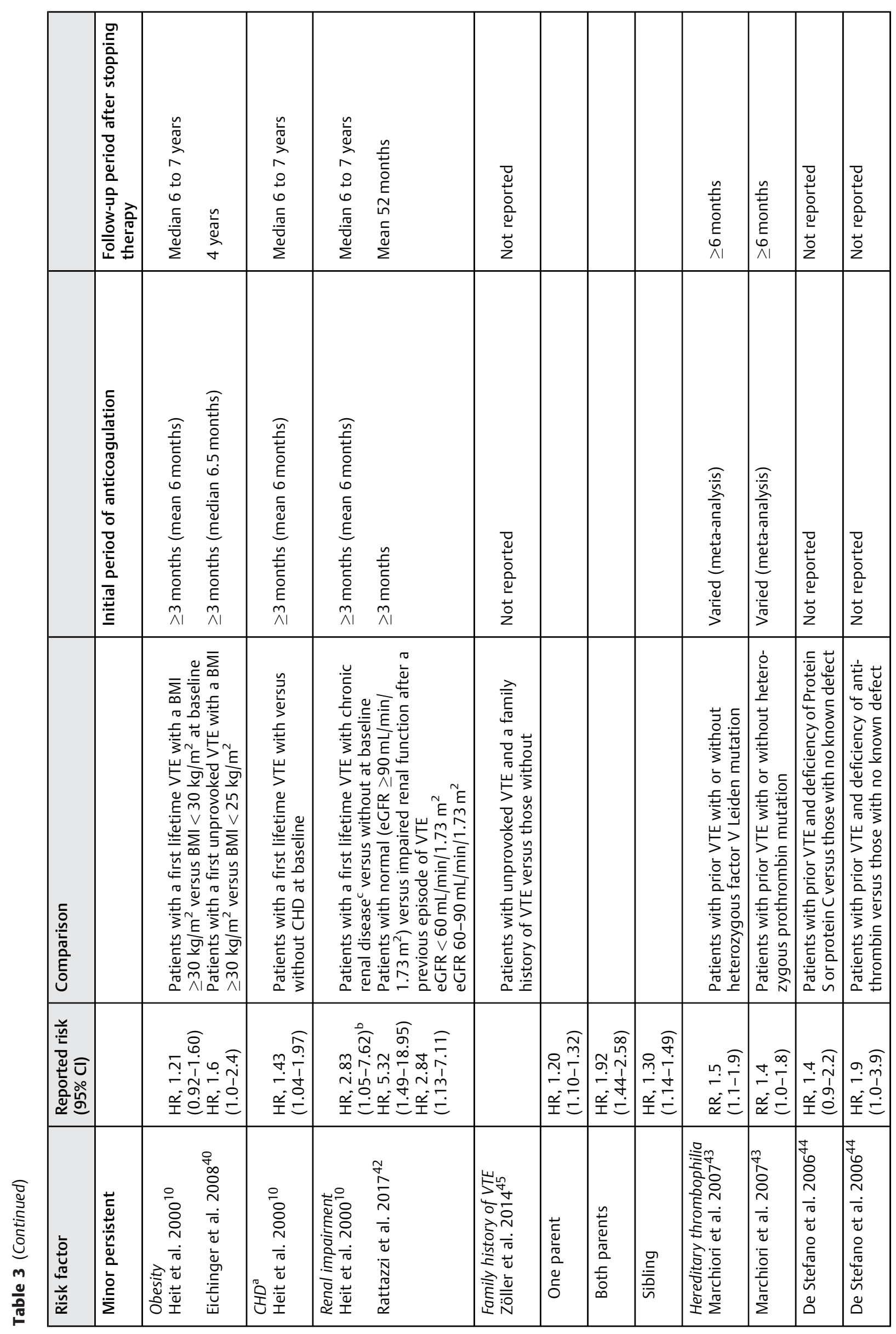



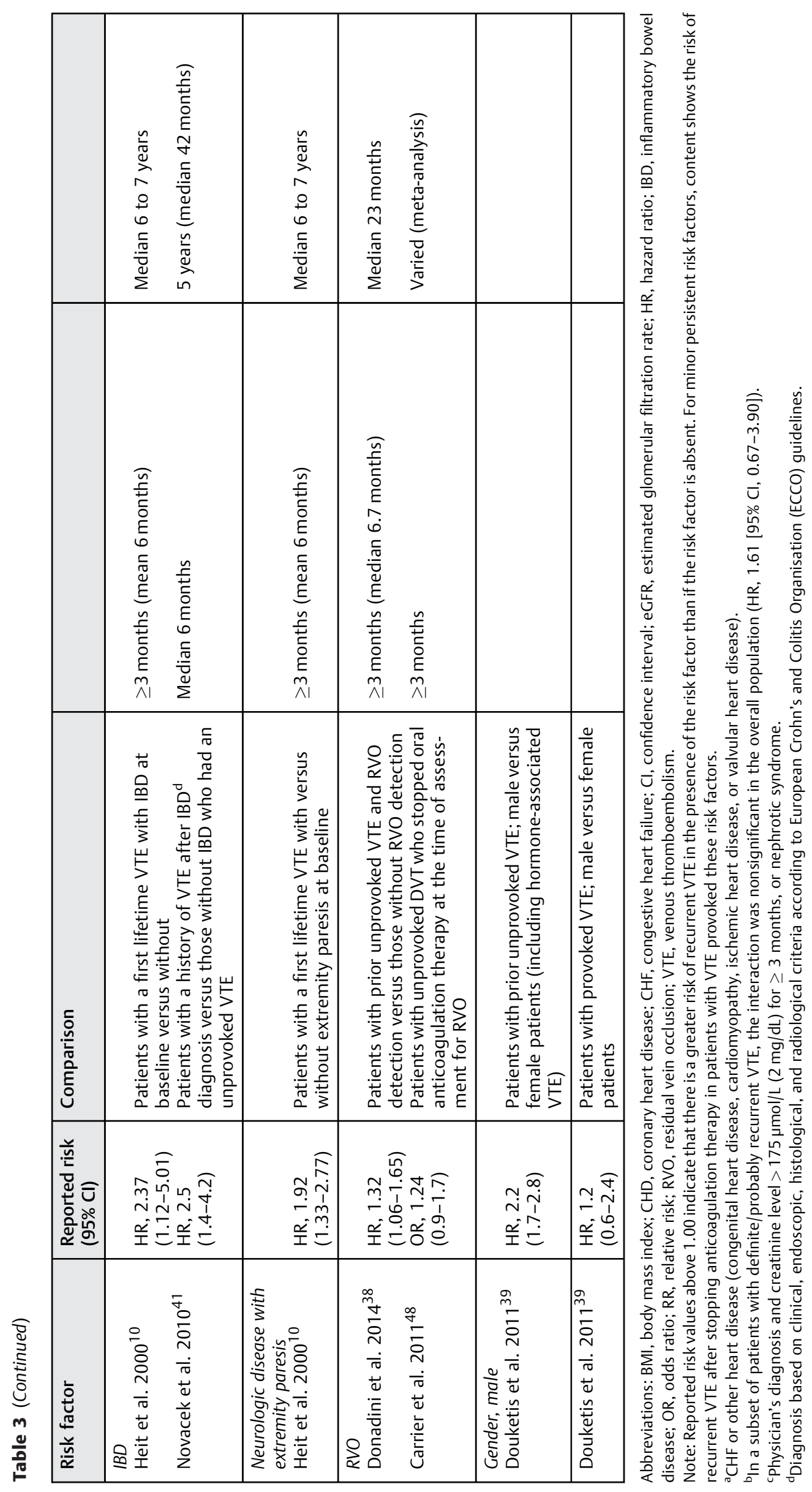
studies, the rate of recurrence if anticoagulation therapy was stopped after $\geq 3$ months of treatment was $4.2 \%$ per patientyear in patients with VTE provoked by a nonsurgical transient risk factor (compared with 0.7 and $7.4 \%$ per-year in VTE provoked by surgery and unprovoked VTE, respectively). ${ }^{11}$ Similarly, in the pooled analysis of EINSTEIN EXT and EINSTEIN CHOICE, the 1-year cumulative incidence of recurrent VTE in patients whose VTE was provoked by a minor transient risk factor was $4.2 \%$ in those who received placebo and $4.2 \%$ in those who received ASA. ${ }^{9}$ For patients who had received rivaroxaban, the 1-year cumulative incidence was $0.4 \%$, suggesting that some patients with VTE provoked by minor transient risk factors may benefit from extended anticoagulation (i.e., if the risk of recurrent VTE outweighs the risk of bleeding). Although overall recurrence rates in patients with VTE provoked by minor transient risk factors were numerically lower than that in patients with unprovoked VTE, the difference was not statistically significant (HR, 0.68; 95\% CI, 0.32-1.30). Therefore, additional studies are needed to further delineate and confirm the individual factors that warrant such an approach.

\section{Minor Persistent Risk Factors}

Minor persistent risk factors for VTE recurrence include IBD, lower extremity paralysis or paresis, CHF, chronic kidney disease, BMI $>30 \mathrm{~kg} / \mathrm{m}^{2}$, hereditary and acquired thrombophilia, a family history of VTE, residual vein occlusion (RVO), and male gender. ${ }^{9,10,38,39} \mathrm{~A}$ list of minor persistent risk factors and the associated risk of recurrence after stopping anticoagulation therapy is shown in - Table $\mathbf{3}$.

In a retrospective, population-based cohort study, the risk of recurrent VTE over 6 to 7 years of follow-up was evaluated in patients who had received a mean duration of 6 months of anticoagulation therapy for VTE. Minor persistent risk factors for VTE at baseline associated with an increased risk of recurrence included IBD (HR, 2.37; 95\% CI, 1.12-5.01), neurological disease associated with extremity paresis (HR, 1.92; 95\% CI, 1.33-2.77), and CHF (HR, 1.43; 95\% CI, 1.04-1.97). Chronic kidney disease at baseline was a significant predictor of recurrence in a subset of patients with "probably/definite" (as opposed to "possible") VTE recurrence (HR, 2.83; 95\% CI, $1.05-7.62$ ). A BMI of $\geq 30 \mathrm{~kg} / \mathrm{m}^{2}$ was not associated with an increased risk of recurrence in this study. However, in a cohort study of 1,107 patients who had been treated with anticoagulation therapy for $\geq 3$ months, the rate of recurrence after stopping anticoagulation therapy was significantly higher in patients classified as obese (BMI $\geq 30 \mathrm{~kg} / \mathrm{m}^{2}$ ) compared with patients with a BMI of $<25 \mathrm{~kg} / \mathrm{m}^{2}$ (adjusted HR, 1.6; 95\% CI, 1.1-2.4; $p=0.02) .{ }^{40}$

The risk of recurrence in patients with IBD was further evaluated in a prospective study of patients with a first unprovoked VTE. The study included 2,811 patients with IBD (diagnosed in accordance with the European Crohn's and Colitis Organization guidelines) and 1,255 patients without IBD. Patients with IBD had a significantly higher rate of recurrent VTE 5 years after stopping anticoagulant therapy than those without (33.4\% vs. $21.7 \%$, respectively; $p=0.01$ ). ${ }^{41}$ After adjustment for possible confounders, IBD was demon- strated to be an independent risk factor for recurrent VTE (HR, $2.5 ; 95 \% \mathrm{CI}, 1.4-4.2 ; p=0.001$ ). Half of the IBD patients had active disease at the time of recurrent VTE. The impact of decreased renal function on the risk of recurrence was further evaluated in an observational study that prospectively followed a subgroup of 260 patients with VTE who had stopped anticoagulation therapy and had not yet had a recurrence. Compared with patients with normal renal function, the risk was increased in patients with chronic kidney disease (estimated glomerular filtration rate $[\mathrm{eGFR}]<60 \mathrm{~mL} / \mathrm{min} / 1.73 \mathrm{~m}^{2}$; HR, 5.32; 95\% CI, 1.49-18.95; $p=0.010$ ) or more moderate renal disease (eGFR $60-90 \mathrm{~mL} / \mathrm{min} / 1.73 \mathrm{~m}^{2}$; HR, 2.84; $95 \% \mathrm{CI}$, $1.13-7.11 ; p=0.025){ }^{42}$

Regarding hereditary thrombophilia, the risk of recurrent VTE is slightly higher in those heterozygous for the factor V Leiden mutation (HR, 1.5; 95\% CI, 1.1-1.9) or the prothrombin gene mutation (HR, 1.4; 95\% CI, 1.0-1.8) than in those without these mutations. ${ }^{43}$ After adjustment for age, sex, and the circumstances of the initial venous thromboembolic event, the risk of recurrence after stopping anticoagulant therapy was higher in patients with antithrombin deficiency than in patients without (HR, 1.9; $95 \% \mathrm{CI}, 1.0-3.9) .{ }^{44}$ In the same study, there was a marginal increase in the risk of recurrence in patients with protein $\mathrm{C}$ or protein $\mathrm{S}$ deficiency compared with patients without thrombophilia (HR, 1.4; 95\% CI, 0.9-2.2) ${ }^{44}$ In patients with a family history of VTE, a Swedish registry demonstrated that the risk of hospitalization for recurrent VTE was slightly elevated in those with a parental (HR, 1.20; 95\% CI, 1.10-1.32) or sibling (HR, 1.30; 95\% CI, 1.14-1.49) history of VTE versus those with no such history. ${ }^{45}$ In those where both parents had experienced VTE, the risk was further increased versus those with no parental history of VTE (HR, 1.92; 95\% CI, 1.44-2.58). ${ }^{45}$ However, other studies have been unable to demonstrate a connection between recurrence risk and family history of VTE. ${ }^{46}$

The pooled analysis of EINSTEIN EXT and EINSTEIN CHOICE evaluated the risk of VTE recurrence in patients with the minor persistent risk factors outlined above. The 1-year cumulative incidence of recurrent VTE in these patients was $10.7 \%$ in patients who had received placebo, $4.5 \%$ in those who received ASA, and $2.4 \%$ in patients who had received rivaroxaban. The overall rate of recurrence in patients with minor persistent risk factors was statistically similar to that observed with unprovoked VTE (HR, 0.68; 95\% $\mathrm{CI}, 0.32-1.30) .^{9}$ As per discussions regarding minor transient risk factors, results from this analysis suggest that some patients with minor persistent risk factors may benefit from extended anticoagulation therapy.

Additional persistent risk factors to consider include RVO and male gender. The prognostic value of RVO is difficult to assess because of differences in RVO assessment across studies. ${ }^{47}$ A meta-analysis of 2,527 patients from 10 studies investigating the utility of RVO for predicting the risk of recurrence after at least 3 months of anticoagulant therapy for unprovoked VTE found a small association that appeared to be dependent on the time of RVO assessment after the index venous thromboembolic event (HR, 1.32; 95\% CI, 1.06$1.65){ }^{38}$ RVO detected at 3 months was associated with a 
higher risk of recurrent VTE (HR, 2.17; 95\% CI, 1.11-4.25); however, this association was no longer observed after 6 months (HR, 1.19; 95\% CI, 0.87-1.61). ${ }^{38}$ In another metaanalysis, RVO was not associated with an increased risk of recurrent VTE (odds ratio [OR], 1.24; 95\% CI, 0.9-1.7) in patients with unprovoked DVT who stopped oral anticoagulation therapy at the time of assessment for RVO. However, RVO was significantly associated with recurrent VTE in patients with any (unprovoked or provoked) DVT (OR, 1.5; $95 \% \mathrm{CI}, 1.1-2.0) .{ }^{48}$ Finally, in a patient-level meta-analysis of 2,554 patients, a twofold higher risk for VTE recurrence was observed in male patients with unprovoked VTE than in female patients (HR, 2.2; 95\% CI, 1.7-2.8). ${ }^{39}$ This increase in risk remained after exclusion of women with hormoneassociated VTE (HR, 1.8; 95\% CI, 1.4-2.5), but was not observed in patients with provoked VTE (HR, 1.2; 95\% CI, 0.6-2.4). ${ }^{39}$ Therefore, the value of RVO as a predictor of recurrence remains uncertain, but men with unprovoked VTE are at higher risk of recurrence than women.

\section{Optimal Dose of Anticoagulant for Extended Venous Thromboembolism Treatment}

The benefit-risk profile of reduced versus full doses of apixaban or rivaroxaban was examined in a recent meta-analysis that included the AMPLIFY-EXT and EINSTEIN CHOICE trials. Compared with full-dose apixaban or rivaroxaban, the reduceddose regimens were associated with a trend for less clinically relevant bleeding (2.3\% vs. 3.7\%; RR, 0.74; 95\% CI, 0.52-1.05; $p=0.09$ ) and no significant increase in the risk of recurrent VTE (1.6\% vs. $1.4 \%$; RR, $1.12 ; 95 \% \mathrm{CI}, 0.67-1.87 ; p=0.67) .{ }^{49}$

Individual benefit-risk analyses for AMPLIFY-EXT and EINSTEIN CHOICE have also been published. In an analysis of data from AMPLIFY-EXT, it was shown that during the 1 -year study period 14 patients would need to be treated with apixaban to prevent a recurrent fatal or nonfatal venous thromboembolic event, whereas 200 patients would need to receive apixaban for a major bleeding or CRNM bleeding event to occur. $^{26}$ In an analysis of data from EINSTEIN CHOICE, it was revealed that for every 10,000 patients with VTE treated for 1 year with rivaroxaban 20 or $10 \mathrm{mg}$ once daily instead of ASA, 312 (95\% CI, 144-479) and 341 (95\% CI, 175-507) fewer recurrent venous thromboembolic events would result, respectively (number needed to treat 33 and 30 patients, respectively). ${ }^{34}$ In terms of safety, for every
10,000 patients who received rivaroxaban 20 or $10 \mathrm{mg}$ once daily for 1 year instead of ASA there would be 28 ( $95 \% \mathrm{CI},-43$ to 99 ) and 0 ( $95 \% \mathrm{CI},-60$ to 59$)$ more major bleeding events, respectively (number needed to harm 356 and 0 , respectively). With rivaroxaban $10 \mathrm{mg}$ once daily it would take nearly 60,000 patients to be treated to cause an additional bleeding event. Therefore, the reduced-dose regimens of apixaban or rivaroxaban appear to provide greater safety than full doses, without loss of efficacy.

With regard to the impact of minor persistent and transient risk factors, the EINSTEIN CHOICE study analyzed benefit-risk data in more detail in 3,365 patients with VTE treated with rivaroxaban (20 or $10 \mathrm{mg}$ ) or ASA. ${ }^{34}$ Results of this analysis are shown in - Table $\mathbf{4}$, and translate into an annual net clinical benefit that favors the use of rivaroxaban $10 \mathrm{mg}$ over the use of rivaroxaban $20 \mathrm{mg}$ for continued therapy in patients with clinical equipoise for extended therapy. The number needed to treat to prevent one additional event with rivaroxaban $20 \mathrm{mg}$ versus $10 \mathrm{mg}$ being 33 and 24 patients (unprovoked VTE), 49 and 42 patients (VTE by minor persistent risk factors), and 35 and 29 patients (VTE by minor transient risk factors), respectively. For the remaining DOACs, no such subanalysis regarding minor VTE risk factors has been reported.

\section{Selecting the Right Dose for the Right Patient: Clinical and Practical Considerations on Extended Venous Thromboembolism Treatment Dosing}

How should physicians select the best dose for each patient? All patients with VTE require at least 3 months of anticoagulant therapy. The decision to extend anticoagulation therapy beyond 3 months depends on the balance between the risk of recurrence if anticoagulation therapy is stopped and the risk of bleeding if it is continued. For extended therapy, most patients treated with apixaban or rivaroxaban can be switched to the low-dose regimens. We advise delaying this switch until patients have completed at least 6 months of treatment with the full-dose regimen because earlier initiation of the lower-dose regimens has not been evaluated. Patients who should remain on the high-dose regimens include those who have had a recurrence on a reduced-dose regimen and those at high risk of recurrence such as patients with active cancer or those with thrombophilic disorders, because such patients

Table 4 Numbers of fewer than expected recurrent venous thromboembolic events and additional expected major bleeding events with rivaroxaban 20 and $10 \mathrm{mg}$ compared with ASA in the ENSTEIN CHOICE trial ${ }^{34}$

\begin{tabular}{|c|c|c|c|c|c|c|}
\hline$n(95 \% \mathrm{Cl})$ & \multicolumn{2}{|l|}{ Unprovoked VTE } & \multicolumn{2}{|c|}{ Minor persistent } & \multicolumn{2}{|l|}{ Minor transient } \\
\hline $\begin{array}{l}\text { Rivaroxaban } \\
\text { dose }\end{array}$ & $20 \mathrm{mg}$ & $10 \mathrm{mg}$ & $20 \mathrm{mg}$ & $10 \mathrm{mg}$ & $20 \mathrm{mg}$ & $10 \mathrm{mg}$ \\
\hline $\begin{array}{l}\text { Recurrent } \\
\text { VTE }\end{array}$ & $\begin{array}{l}386 \\
(-646 \text { to }-125)\end{array}$ & $\begin{array}{l}419 \\
(-672 \text { to }-167)\end{array}$ & $\begin{array}{l}226 \\
(-503 \text { to } 51)\end{array}$ & $\begin{array}{l}243 \\
(-533 \text { to } 46)\end{array}$ & $\begin{array}{l}323 \\
(-775 \text { to } 130)\end{array}$ & $\begin{array}{l}419 \\
(-831 \text { to }-7)\end{array}$ \\
\hline $\begin{array}{l}\text { Major } \\
\text { bleeding }\end{array}$ & $\begin{array}{l}75 \\
(-29 \text { to } 179)\end{array}$ & $\begin{array}{l}21 \\
(-52 \text { to } 93)\end{array}$ & $\begin{array}{l}21 \\
(-20 \text { to } 63)\end{array}$ & 0 & $\begin{array}{l}150 \\
(-308 \text { to } 609)\end{array}$ & $\begin{array}{l}72 \\
(-299 \text { to } 443)\end{array}$ \\
\hline
\end{tabular}

Abbreviations: ASA, acetylsalicylic acid; $\mathrm{Cl}$, confidence interval; VTE, venous thromboembolism. 


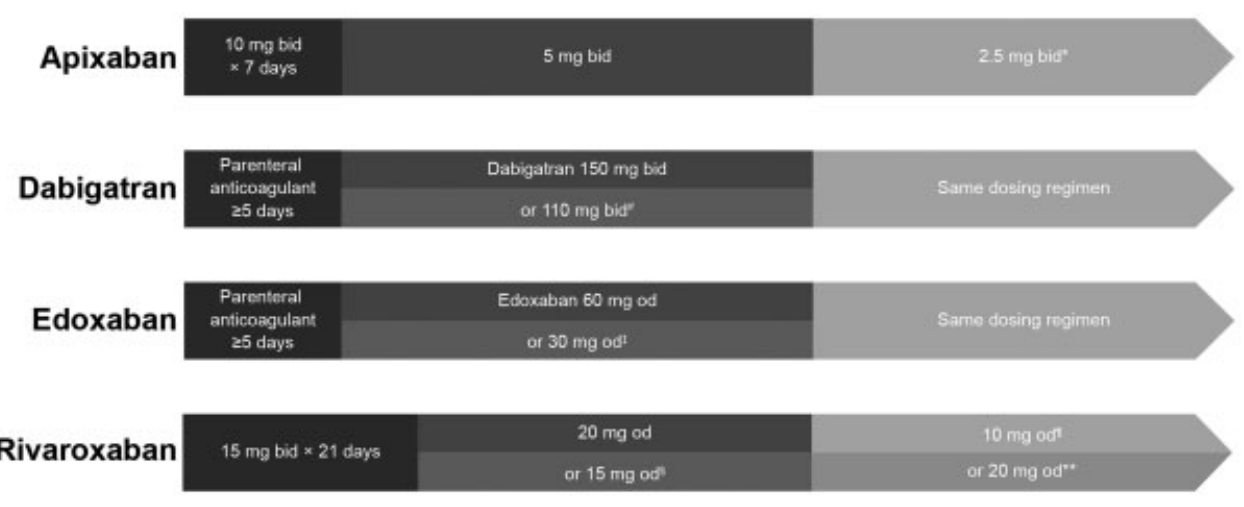

Initial treatment

Fig. 1 Dosing schedules for the four direct oral anticoagulants for initial, long-term and extended VTE treatment. *2.5 mg bid extended dose initiated following completion of 6 months of treatment with apixaban $5 \mathrm{mg}$ bid or with another anticoagulant; " Dose reduction recommended in patients aged $\geq 80$ years old or who receive concomitant verapamil; dose reduction should be considered in patients aged $75-80$ years old, with moderate renal impairment $(\mathrm{CrCl} 30-50 \mathrm{~mL} / \mathrm{min})$, gastritis, esophagitis or gastroesophageal reflux, or other patients at an increased risk of bleeding; *Dose reduction recommended in patients with moderate renal impairment $(\mathrm{CrCl} 15-50 \mathrm{~mL} / \mathrm{min})$, low body weight $(\leq 60 \mathrm{~kg})$, or who receive concomitant P-glycoprotein inhibitors; ${ }^{\S}$ In patients with $\mathrm{CrCl} 15-49 \mathrm{~mL} / \mathrm{min}$ if the patient's assessed risk of bleeding outweighs that of VTE; ${ }^{\top 1} 10 \mathrm{mg}$ od extended dose initiated following completion of at least 6 months' therapy for DVT or PE; **Dose increase should be considered in patients with a high risk of recurrent DVT or PE, such as those with complicated comorbidities or those who have developed recurrent VTE on extended prevention with rivaroxaban $10 \mathrm{mg}$ od. bid, twice daily; $\mathrm{CrCl}$, creatinine clearance; DVT, deep vein thrombosis; od, once daily; PE, pulmonary embolism; VTE, venous thromboembolism.

were underrepresented in the extended treatment trials. Patient preference also needs to be considered. For example, selection of a reduced-dose regimen may provide reassurance for patients with a history of bleeding, or for those participating in contact sports or those who work under hazardous conditions. In contrast, continuation of the full-dose regimen may provide reassurance for the VTE patient with life-threatening PE or a family history of fatal PE. Patients also have the option to re-escalate to a higher dosage if required. Therefore, with the choice of two-dose regimens, selection can be personalized based on individual benefit-risk considerations. An overview of the dosing guidance for the four DOACs for extended treatment from their respective product labels DOACs is provided in $\mathbf{- F i g . ~} \mathbf{1}$.

The optimal duration of anticoagulation in patients with VTE provoked by minor transient or persistent risk factors is uncertain, but some of these patients are likely to need extended treatment similar to those with unprovoked VTE. Additional studies are needed to identify the highest risk minor transient or persistent risk factors. Regardless, regular assessment of risk factors for VTE and bleeding and regular conversations with the patient on their preferences regarding dose and duration of therapy are key to best outcomes for patients.

A further point to note is that the 2016 International Society on Thrombosis and Haemostasis Scientific and Standardization Committee guidance on the use of DOACs in obese patients suggests that DOACs should not be used in patients with a BMI of $>40 \mathrm{~kg} / \mathrm{m}^{2}$ and weight $>120 \mathrm{~kg}$ for VTE treatment because of a possible risk of underdosing and a lack of clinical evidence for DOAC use at the extremes of body weight. ${ }^{50}$ However, the European and North American product labels for apixaban, dabigatran, edoxaban, and rivaroxaban do not restrict use of DOACs for high weight or BMI. ${ }^{30,32,51-55}$ This is based on the fact that body weight had little influence on plasma concentrations of DOACs in pharmacokinetic/pharmacodynamic studies. In a recently published analysis of 3,458 patients taking a DOAC prior to admission to a single health system between February 2013 and August 2016, obesity did not significantly correlate with thrombotic or overt bleeding complications. ${ }^{56}$ However, further research is still needed, especially considering that patients who are obese often have additional comorbidities, which may affect the risk of thrombosis and/or bleeding. In fact, all relevant factors should be considered when choosing the optimal dose of DOAC therapy for long-term and extended therapy.

\section{Conclusion and Future Directions}

Extended treatment studies and subanalyses of phase III studies of patients receiving longer-duration therapy are now available for the four DOACs across a broad range of patients. The option for reduced doses of rivaroxaban and apixaban for extended therapy offers VTE prophylaxis with little increase in bleeding risk, which helps to tailor treatment to the needs of specific patients. The availability of two rivaroxaban and apixaban dosing regimens coupled with the option for dose re-escalation from the low dose to the full dose gives flexibility to meet patient preferences and physician recommendations. Analysis of more granular definitions for risk factor groupings than those used in the traditional schema of provoked versus unprovoked VTE has also yielded vital information on the most appropriate strategies for the treatment of patients with specific risk factors. Such analyses highlight the fact that extended 
anticoagulation treatment may benefit those with VTE provoked by minor transient and persistent environmental and nonenvironmental risk factors who commonly receive shorter-duration therapy. The findings described in this review are likely to influence future updates to clinical guidelines for long-term VTE treatment. Finally, for some patients, there still exists a degree of uncertainty as to the optimal approach for extended therapy; therefore, future studies will be important to refine the best management strategies for such patients.

\section{Funding}

This study was funded by Bayer AG.

\section{Conflict of interest}

M.S. has received speaker fees from Abbott, Aspen, Boston Scientific, Bristol-Myers Squibb, Daiichi Sankyo, GlaxoSmithKline, and Sanofi; travel grants from Bard, Bayer, Bristol-Myers Squibb, Medtronic, and Terumo; research grants from Cook, Daiichi Sankyo, and Terumo; and consulting fees from Bayer, Bristol-Myers Squibb, Daiichi Sankyo, and Sanofi. J.W. has received consultancy fees and honoraria from Bayer, Boehringer Ingelheim, Bristol-Myers Squibb, Daiichi Sankyo, Ionis, Janssen, Merck, Novartis, Pfizer, Portola, Anthos, and Tetherex.

\section{Acknowledgments}

The authors would like to acknowledge Kate Weatherall from Chameleon Communications International, who provided editorial assistance with the preparation of the manuscript, with funding from Bayer AG.

\section{References}

1 Heit JA. Epidemiology of venous thromboembolism. Nat Rev Cardiol 2015;12(08):464-474

2 Cohen AT, Agnelli G, Anderson FA, et al; VTE Impact Assessment Group in Europe (VITAE). Venous thromboembolism (VTE) in Europe. The number of VTE events and associated morbidity and mortality. Thromb Haemost 2007;98(04):756-764

3 Konstantinides SV, Torbicki A, Agnelli G, et al; Task Force for the Diagnosis and Management of Acute Pulmonary Embolism of the European Society of Cardiology (ESC). 2014 ESC guidelines on the diagnosis and management of acute pulmonary embolism. Eur Heart J 2014;35(43):3033-3069

4 Kearon C, Akl EA. Duration of anticoagulant therapy for deep vein thrombosis and pulmonary embolism. Blood 2014;123(12): 1794-1801

5 Kearon C, Ageno W, Cannegieter SC, Cosmi B, Geersing GJ, Kyrle PA; Subcommittees on Control of Anticoagulation, and Predictive and Diagnostic Variables in Thrombotic Disease. Categorization of patients as having provoked or unprovoked venous thromboembolism: guidance from the SSC of ISTH. J Thromb Haemost 2016; 14(07):1480-1483

6 Kearon C, Akl EA, Ornelas J, et al. Antithrombotic therapy for VTE disease: CHEST guideline and expert panel report. Chest 2016; 149(02):315-352

7 Mazzolai L, Aboyans V, Ageno W, et al. Diagnosis and management of acute deep vein thrombosis: a joint consensus document from the European Society of Cardiology working groups of aorta and peripheral vascular diseases and pulmonary circulation and right ventricular function. Eur Heart J 2018;39(47):4208-4218
8 Boutitie F, Pinede L, Schulman S, et al. Influence of preceding length of anticoagulant treatment and initial presentation of venous thromboembolism on risk of recurrence after stopping treatment: analysis of individual participants' data from seven trials. BMJ 2011;342:d3036

9 Prins MH, Lensing AWA, Prandoni P, et al. Risk of recurrent venous thromboembolism according to baseline risk factor profiles. Blood Adv 2018;2(07):788-796

10 Heit JA, Mohr DN, Silverstein MD, Petterson TM, O'Fallon WM, Melton LJ III. Predictors of recurrence after deep vein thrombosis and pulmonary embolism: a population-based cohort study. Arch Intern Med 2000;160(06):761-768

11 Iorio A, Kearon C, Filippucci E, et al. Risk of recurrence after a first episode of symptomatic venous thromboembolism provoked by a transient risk factor: a systematic review. Arch Intern Med 2010; 170(19):1710-1716

12 Hutten BA, Prins MH. Duration of treatment with vitamin K antagonists in symptomatic venous thromboembolism. Cochrane Database Syst Rev 2006;(01):CD001367

13 Middeldorp S, Prins MH, Hutten BA. Duration of treatment with vitamin $\mathrm{K}$ antagonists in symptomatic venous thromboembolism. Cochrane Database Syst Rev 2014;(08):CD001367

14 Ridker PM, Goldhaber SZ, Danielson E, et al; PREVENT Investigators. Long-term, low-intensity warfarin therapy for the prevention of recurrent venous thromboembolism. N Engl J Med 2003;348(15):1425-1434

15 Kearon C, Ginsberg JS, Kovacs MJ, et al; Extended Low-Intensity Anticoagulation for Thrombo-Embolism Investigators. Comparison of low-intensity warfarin therapy with conventional-intensity warfarin therapy for long-term prevention of recurrent venous thromboembolism. N Engl J Med 2003;349(07):631-639

16 Amin A, Marrs JC. Direct oral anticoagulants for the management of thromboembolic disorders: the importance of adherence and persistence in achieving beneficial outcomes. Clin Appl Thromb Hemost 2016;22(07):605-616

17 van der Hulle T, den Exter PL, Kooiman J, van der Hoeven JJ, Huisman MV, Klok FA. Meta-analysis of the efficacy and safety of new oral anticoagulants in patients with cancer-associated acute venous thromboembolism. J Thromb Haemost 2014;12(07):1116-1120

18 Prins MH, Lensing AWA, Brighton TA, et al. Oral rivaroxaban versus enoxaparin with vitamin $\mathrm{K}$ antagonist for the treatment of symptomatic venous thromboembolism in patients with cancer (EINSTEIN-DVT and EINSTEIN-PE): a pooled subgroup analysis of two randomised controlled trials. Lancet Haematol 2014;1(01):e37-e46

19 van Es N, Coppens M, Schulman S, Middeldorp S, Büller HR. Direct oral anticoagulants compared with vitamin $\mathrm{K}$ antagonists for acute venous thromboembolism: evidence from phase 3 trials. Blood 2014;124(12):1968-1975

20 Bauersachs R, Gitt AK, Mismetti P, et al. Readmittance to hospital within 6 months after a venous thromboembolism event: PREFER in VTE registry. Value Health 2014;17(07):A472-A473

21 Di Nisio M, Vedovati MC, Riera-Mestre A, et al. Treatment of venous thromboembolism with rivaroxaban in relation to body weight. A sub-analysis of the EINSTEIN DVT/PE studies. Thromb Haemost 2016;116(04):739-746

22 Agnelli G, Buller HR, Cohen A, et al. Oral apixaban for the treatment of venous thromboembolism in cancer patients: results from the AMPLIFY trial. J Thromb Haemost 2015;13(12): 2187-2191

23 Goldhaber SZ, Eriksson H, Kakkar A, et al. Efficacy of dabigatran versus warfarin in patients with acute venous thromboembolism in the presence of thrombophilia: findings from RE-COVER ${ }^{\circledR}$, RECOVER $^{\mathrm{TM}}$ II, and RE-MEDYTM. Vasc Med 2016;21(06):506-514

24 Schulman S, Goldhaber SZ, Kearon C, et al. Treatment with dabigatran or warfarin in patients with venous thromboembolism and cancer. Thromb Haemost 2015;114(01):150-157

25 Schulman S, Kearon C, Kakkar AK, et al; RE-MEDY Trial Investigators; RE-SONATE Trial Investigators. Extended use of dabigatran, 
warfarin, or placebo in venous thromboembolism. N Engl J Med 2013;368(08):709-718

26 Agnelli G, Buller HR, Cohen A, et al; AMPLIFY-EXT Investigators. Apixaban for extended treatment of venous thromboembolism. N Engl J Med 2013;368(08):699-708

27 Bauersachs R, Berkowitz SD, Brenner B, et al; EINSTEIN Investigators. Oral rivaroxaban for symptomatic venous thromboembolism. N Engl J Med 2010;363(26):2499-2510

28 Weitz JI, Lensing AWA, Prins MH, et al; EINSTEIN CHOICE Investigators. Rivaroxaban or aspirin for extended treatment of venous thromboembolism. N Engl J Med 2017;376(13):1211-1222

29 Raskob G, Ageno W, Cohen AT, et al. Extended duration of anticoagulation with edoxaban in patients with venous thromboembolism: a post-hoc analysis of the Hokusai-VTE study. Lancet Haematol 2016;3(05):e228-e236

30 Bristol-Myers Squibb. Pfizer. Eliquis ${ }^{\circledR}$ (apixaban) Summary of Product Characteristics. 2019. Available at: http://www.ema.europa.eu/docs/ en_GB/document_library/EPAR_-_Product_Information/human/002 148/WC500107728.pdf. Accessed August 29, 2019

31 Simes J, Becattini C, Agnelli G, et al; INSPIRE Study Investigators (International Collaboration of Aspirin Trials for Recurrent Venous Thromboembolism). Aspirin for the prevention of recurrent venous thromboembolism: the INSPIRE collaboration. Circulation 2014;130(13):1062-1071

32 Bayer AG. Xarelto ${ }^{\circledR}$ (rivaroxaban) Summary of Product Characteristics. 2019. Available at: https://www.ema.europa.eu/documents/ product-information/xarelto-epar-product-information_en.pdf. Accessed August 29, 2019

33 Janssen Pharmaceuticals Inc. Xarelto ${ }^{\circledR}$ (rivaroxaban) Prescribing Information. 2019. Available at: http://www.janssenlabels.com/ package-insert/product-monograph/prescribing-information/XAR ELTO-pi.pdf. Accessed August 29, 2019

34 Prandoni P, Lensing AWA, Prins MH, et al. Benefits and risks of extended treatment of venous thromboembolism with rivaroxaban or with aspirin. Thromb Res 2018;168:121-129

35 Büller HR, Décousus H, Grosso MA, et al; Hokusai-VTE Investigators. Edoxaban versus warfarin for the treatment of symptomatic venous thromboembolism. N Engl J Med 2013;369(15): 1406-1415

36 Peñaloza-Martínez E, Demelo-Rodríguez P, Proietti M, et al. Update on extended treatment for venous thromboembolism. Ann Med 2018;50(08):666-674

37 Prandoni P, Noventa F, Ghirarduzzi A, et al. The risk of recurrent venous thromboembolism after discontinuing anticoagulation in patients with acute proximal deep vein thrombosis or pulmonary embolism. A prospective cohort study in 1,626 patients. Haematologica 2007;92(02):199-205

38 Donadini MP, Ageno W, Antonucci E, et al. Prognostic significance of residual venous obstruction in patients with treated unprovoked deep vein thrombosis: a patient-level meta-analysis. Thromb Haemost 2014;111(01):172-179

39 Douketis J, Tosetto A, Marcucci M, et al. Risk of recurrence after venous thromboembolism in men and women: patient level meta-analysis. BMJ 2011;342:d813

40 Eichinger S, Hron G, Bialonczyk C, et al. Overweight, obesity, and the risk of recurrent venous thromboembolism. Arch Intern Med 2008;168(15):1678-1683

41 Novacek G, Weltermann A, Sobala A, et al. Inflammatory bowel disease is a risk factor for recurrent venous thromboembolism. Gastroenterology 2010;139(03):779-787

42 Rattazzi M, Villalta S, De Lucchi L, et al. Chronic kidney disease is associated with increased risk of venous thromboembolism recurrence. Thromb Res 2017;160:32-37

43 Marchiori A, Mosena L, Prins MH, Prandoni P. The risk of recurrent venous thromboembolism among heterozygous carriers of factor V Leiden or prothrombin G20210A mutation. A systematic review of prospective studies. Haematologica 2007;92(08): $1107-1114$
44 De Stefano V, Simioni P, Rossi E, et al. The risk of recurrent venous thromboembolism in patients with inherited deficiency of natural anticoagulants antithrombin, protein $C$ and protein S. Haematologica 2006;91(05):695-698

45 Zöller B, Ohlsson H, Sundquist J, Sundquist K. Family history of venous thromboembolism (VTE) and risk of recurrent hospitalization for VTE: a nationwide family study in Sweden. J Thromb Haemost 2014;12(03):306-312

46 Hron G, Eichinger S, Weltermann A, et al. Family history for venous thromboembolism and the risk for recurrence. Am J Med 2006;119(01):50-53

47 Streiff MB. Predicting the risk of recurrent venous thromboembolism (VTE). J Thromb Thrombolysis 2015;39(03):353-366

48 Carrier M, Rodger MA, Wells PS, Righini M, LE Gal G. Residual vein obstruction to predict the risk of recurrent venous thromboembolism in patients with deep vein thrombosis: a systematic review and meta-analysis. J Thromb Haemost 2011;9(06):1119-1125

49 Vasanthamohan L, Boonyawat K, Chai-Adisaksopha C, Crowther M. Reduced-dose direct oral anticoagulants in the extended treatment of venous thromboembolism: a systematic review and meta-analysis. J Thromb Haemost 2018;16(07):1288-1295

50 Martin K, Beyer-Westendorf J, Davidson BL, Huisman MV, Sandset PM, Moll S. Use of the direct oral anticoagulants in obese patients: guidance from the SSC of the ISTH. J Thromb Haemost 2016;14 (06):1308-1313

51 Bristol-Myers Squibb Company. Pfizer Inc. Eliquis ${ }^{\circledR}$ (apixaban) Prescribing information. 2019. Available at: http://packageinserts.bms.com/pi/pi_eliquis.pdf. Accessed August 29, 2019

52 Daiichi Sankyo Europe Gmb H. Lixiana ${ }^{\circledR}$ (edoxaban) Summary of Product Characteristics. 2019. Available at: http://www.ema.europa. eu/docs/en_GB/document_library/EPAR_-_Product_Information/human/002629/WC500189045.pdf. Accessed August 29, 2019

53 Daiichi Sankyo Inc. Savaysa ${ }^{\circledR}$ (edoxaban) Prescribing information. 2017. Available at: http://dsi.com/prescribing-information-portlet/getPIContent? productName $=$ Savaysa\&inline $=$ true. Accessed August 29, 2018

54 Boehringer Ingelheim International GmbH. Pradaxa ${ }^{\circledR}$ (dabigatran etexilate) Summary of Product Characteristics. 2019. Available at: http://www.ema.europa.eu/docs/en_GB/document_library/EPAR_-Product_Information/human/000829/WC500041059.pdf. Accessed August 29, 2019

55 Boehringer Ingelheim Pharmaceuticals Inc. Pradax ${ }^{\circledR}$ (dabigatran etexilate) prescribing information. 2018. Available at: http://bidocs. boehringer-ingelheim.com/BIWebAccess/ViewServlet.ser?docBase $=$ renetnt\&folderPath=/Prescribing\%20Information/PIs/Pradaxa/Pr adaxa.pdf. Accessed August 29, 2019

56 Netley J, Howard K, Wilson W. Effects of body mass index on the safety and effectiveness of direct oral anticoagulants: a retrospective review. J Thromb Thrombolysis 2019;48(03):359-365

57 Prandoni P, Villalta S, Tormene D, Spiezia L, Pesavento R. Immobilization resulting from chronic medical diseases: a new risk factor for recurrent venous thromboembolism in anticoagulated patients. J Thromb Haemost 2007;5(08):1786-1787

58 Nemeth B, Timp JF, van Hylckama Vlieg A, Rosendaal FR, Cannegieter SC. High risk of recurrent venous thrombosis in patients with lower-leg cast immobilization. J Thromb Haemost 2018;16 (11):2218-2222

59 Pabinger I, Grafenhofer H, Kyrle PA, et al. Temporary increase in the risk for recurrence during pregnancy in women with a history of venous thromboembolism. Blood 2002;100(03):1060-1062

60 De Stefano V, Martinelli I, Rossi E, et al. The risk of recurrent venous thromboembolism in pregnancy and puerperium without antithrombotic prophylaxis. $\mathrm{Br} \mathrm{J}$ Haematol 2006;135(03): 386-391

61 Olié V, Plu-Bureau G, Conard J, Horellou MH, Canonico M, Scarabin PY. Hormone therapy and recurrence of venous thromboembolism among postmenopausal women. Menopause 2011;18(05): 488-493 